\title{
PAISAGEM URBANA DA ZONA NORTE DO RIO: O CASO DO MEIER
}

\author{
VERA REGINA TÂNGARI
}




\section{RESUMO}

artigo apresenta a metodologia utilizada para o projeto de intervenção paisagística no centro funcional do Meier, bairro situado na região norte do Rio de Janeiro junto à linha férrea, tendo como base determinados princípios conceituais que reforçam a relação existente entre desenho urbano e paisagem.

Paralelamente à descrição da abordagem adotada pela equipe, o desenvolvimento do projeto é ilustrado através de croquis e desenhos referentes às fases de caracterização e qualificação paisagísticas, formulação de diretrizes de intervenção e anteprojeto, tendo sido extraídos do conjunto de informações e documentos que integram os volumes do projeto encaminhados à Administração Municipal.

\section{ABSTRACT}

T his article describes the methodology applied to the urban landscape project developed to the Central District of Meier, a neighborhood located in the north sector of Rio de Janeiro, close to the railway track. The conceptual aspects behind the methods and tools chosen reinforce the idea that there is a strong relationship between urban design and landscape configuration.

Besides presenting the approach held by the professionals, the design process itself is shown through sketches, schemes and photographs which illustrate the phases of: survey, analysis and landscape qualification; concept formulation and preliminary design. The elements utilized in the article correspond to a set of data, documents and drawings extracted from the project reports delivered to the Municipal Government. 


\section{INTRODUÇÃO}

A formação das áreas livres de edificação, na cidade do Rio
de Janeiro, é fortemente condicionada pela legislação urbanís-
tica incidente que, ao definir a volumetria básica dos espaços
construídos, induz diretamente a conformação dos não
construídos, seu aproveitamento e sua qualidade ambiental. A
densidade construtiva, e conseqüente adensamento
populacional, a delimitação do espaço físico das ruas e calça-
das, dos recuos, afastamentos e alinhamentos, a determinação
dos prismas e gabaritos, dos usos e atividades permitidos, enfim,
dos parâmetros edilícios legais moldam enquadramentos
paisagísticos peculiares e distintos para cada trecho da cidade.

Paralelamente à legislação urbanística, outros fatores competem para moldar e qualificar a paisagem dos espaços livres, em especial, de uso público:

- as definições quanto ao sistema de circulação viária, o volume e a característica do tráfego de veículos e pedestres;

- o perfil do uso residencial existente;

- o tipo e a intensidade das atividades comerciais e de serviços desenvolvidas;

- o aspecto sócioculturạl da população;

- o suporte físico-natural, definido pelo relevo, topografia e pedologia da região;

- a incidência de vegetação, principalmente no que se refere à arborização viária e ao tratamento de praças e largos;

- a tipologia arquitetônica das edificações;

- a existência de marcos e referenciais, construídos e não construídos, artificiais e naturais;

- as cores e texturas apresentadas por elementos fixos como "pisos" (passeios e ruas), "paredes" (fachadas, empenas, árvores, cartazes, etc.) e "tetos" (passagens, viadutos, passarelas, copas de árvores, etc.), mobiliário, equipamentos e sinalização, e pelos elementos dinâmicos como pessoas e veículos. 
Portanto, além da definição tradicional sobre o objeto de análise da paisagem urbana, buscamos reforçar o conceito de que há uma estreita relação entre o desenho do espaço construído e do espaço não construído, entre a percepção da paisagem e a formação da imagem da cidade; entre composição paisagística e identificação simbólica, entre qualidade ambiental e apropriação dos espaços públicos, entre tratamento paisagístico e a definição de "lugar"

Em conseqüência, é difícil dissociar e isolar o trabalho do paisagista, num projeto de intervenção urbana, cabendo a esse profissional o papel de articulador das propostas espaciais de desenho urbano e de arquitetura, com as de mobiliário e comunicação visual, sendo freqüentemente difícil delimitar a linha de transição entre um campo e o outro.

No caso específico do Meier, conforme será ilustrado mais adiante, buscou-se estudar, tanto em termos de levantamentos e diagnósticos como de intervenções, além dos elementos individuais definidores da paisagem descritos acima, suas interrelações e interferências. Estas foram analisadas através do registro e identificação de enquadramentos e conjuntos paisagísticos, moldados pela conformação do espaço construído, pelo tipo e incidência das áreas não construídas, pela sua articulação espacial, pela configuração do relevo e topografia e característica da vegetação existente, pela qualificação das imagens percebidas e pelo valor simbólico que denotam.

Neste trabalho, procuramos descrever a metodologia utilizada para a avaliação e intervenção na paisagem do centro funcional do Meier, bairro situado na zona norte do Rio de Janeiro, junto à ferrovia EFCB. O projeto está em fase de elaboração para o IPLANRIO e faz parte do escopo do RIO CIDADE, concurso público promovido pela Prefeitura Municipal para dezessete eixos comerciais, tendo sido implementado em duas fases: a primeira, referente às propostas metodológicas; e a segunda, destinada à elaboração de projetos urbanos para bairros específicos. 
Propõe-se, inicialmente, discutir a relação existente entre desenho urbano e paisagem, objetivando, com isso, colaborar para a melhor definição do campo de atuação, do escopo e da abrangência do trabalho de paisagismo, num projeto de intervenção urbana desse tipo.

A título de verificação, após descrever a abordagem e a conceituação adotadas pela equipe, procuramos ilustrar o desenvolvimento do projeto, finalizado em setembro de 1995.

\section{DESENHO URBANO E PAISAGEM: ALGUMAS CONSIDERAÇÕES}

Durante as décadas de 60 e 70, os esforços para formar uma definição clara sobre desenho urbano foram objeto de discussões, pesquisas e trabalhos, no meio acadêmico e profissional, buscando aprofundar esse campo e melhor situá-lo no contexto do planejamento das cidades.

Mais recentemente, o corpo teórico, conceitual e metodológico dessa disciplina foi ampliado, tendo sido acumulado um grande volume de conhecimentos e experiências que embasam a formação do campo disciplinar, sua abrangência de análise e de atuação. (Del Rio, 1990)

Uma nova discussão, no entanto, ganha expressão entre profissionais e acadêmicos: a interrelação e a superposição existentes entre o desenho do espaço físico das cidades e o tratamento da paisagem.

No primeiro caso, a diferenciação entre planejamento e desenho urbano se faz, na maioria das vezes, através da distinção entre os universos de análise, as escalas de atuação e percepção, os processos metodológicos e os resultados projetuais.

No segundo caso, os objetos de intervenção, a conceituação teórica, os métodos de análise e de leitura do espaço se assemelham e se confundem, tornando difícil a tarefa de distin- 
guir os campos disciplinares de desenho urbano ede paisagismo, quando o universo de atuação é a cidade. Se cada vez mais difunde-se a estreita relação entre habitat e paisagem, como separar dois campos que, em última análise, buscam melhor conhecer e transformar o habitat urbano (Ceniquel,1992). Tal distinção se faz especialmente difícil ao levarmos em consideração a formação do paisagista e a definição de suas atribuições. Os profissionais que trabalham com desenho urbano são, via de regra, arquitetos, possuem treinamento específico para trabaIhar com o espaço físico, suas conformações morfológicas e suas leituras perceptivas. Seu universo de análise é a cidade e sua arquitetura.

Os profissionais que trabalham com paisagismo, por sua vez, têm formação diferenciada, congregando, principalmente, botânicos, agrônomos, arquitetos e urbanistas. O corpo de conhecimentos é diversificado, assim como os métodos e objetos de análise, variando enormemente as escalas de intervenção: desde o jardim particular da casa, dentro do lote, até a paisagem da região, dentro do território.

A diferenciação tradicional diz respeito à introdução, no espaço físico, do elemento vegetação que, muitas vezes, é considerado como o único elemento a ser tratado pelo paisagista. $\mathrm{Na}$ verdade, esse é apenas um dos elementos de conformação paisagística, podendo até mesmo não existir. E, ao existir, ganha características quanto a forma, volume, textura, assumindo conotações que vão muito além de suas descrições e especificaçōes botânicas. (Abbud,1986 e Macedo,1992)

Outras definições buscam relacionar as intervenções de desenho urbano com os espaços construídos das cidades e o paisagismo, com os espaços não construídos. Então a discussão giraria em torno do estudo do "cheio" e o estudo do "vazio", entre o "positivo" e o "negativo" em torno da configuração do espaço "abrangido" e a configuração do espaço "abran-gente" (Ashihara, 1982) 
Se defendemos aqui a dicotomia existente entre o espaço construído e as áreas livres de edificação, por estarem, segundo definições bastantes claras e difundidas (Macedo,1984 e Magnoli,1982), totalmente interligados e se autodefinirem, concluímos ser complicado separar as disciplinas de desenho urbano e paisagismo, na escala de atuação da cidade. Defendemos, ao contrário, a estreita conjugação entre a arquitetura do espaço interior e a arquitetura do espaço exterior, entre o habitat físico e o seu contexto social e cultural, entre a formação da cidade, através de suas arquiteturas formais e informais, e a paisagem resultante.

\section{CONCEITOS E MÉTODOS: O CASO DO MEIER}

caráter interdisciplinar proposto pela Prefeitura para o RIO CIDADE, concretizado através do conjunto de estudos e propostas setoriais requisitados pelo IPLANRIO, conjugou-se à postura, defendida pela equipe responsável pela coordenação do projeto, de integrar as intervenções nas áreas de Desenho Urbano, Paisagismo, Mobiliário e Comunicação Visual com as proposições urbanísticas gerais definidas para o bairro ${ }^{1}$

Na primeira fase do concurso, a equipe apresentou o referencial teórico e metodológico para o desenvolvimento do trabalho, estabelecendo critérios de intervenção, de conjugação das propostas setoriais, de participação dos órgãos envolvidos com a comunidade.

Os critérios de intervenção propostos tiveram por princípio básico a implantação e o reforço de determinadas qualidades do espaço urbano, consideradas fundamentais tais como: a identidade visual; a continuidade físico-espacial; a permeabilidade e acessibilidade; o conforto e a adequação aos usuários; a segurança; a estética.

Nesse contexto, o ponto de partida para o projeto de paisagismo foi a definição de conceitos e parâmetros projetuais que estives- 
sem em consonância com os critérios descritos acima e integrados aos demais projetos, possibilitando assim delimitar o escopo e a abrangência do trabalho.

Primeiramente, procuramos identificar o nosso objeto de estudo. No universo proposto pelo RIO CIDADE, que se refere à reestruturação de determinados eixos viários localizados em centros de comércio e serviços de bairros, consideramos que a análise da paisagem deve se fazer a partir da identificação e qualificação dos espaços livres de uso público. O conjunto desses espaços é representado, nesse caso, por ruas, praças, becos e largos, passagens formais e informais existentes.

Dentro desse conjunto, as ruas ganham importância e enfoque especial, já que nelas ocorrem as atividades comerciais, e também porque representam, no caso específico do Meier, onde há pouca incidência de áreas livres, a opção direta de criação e desenvolvimento de espaços de uso comum.

\section{CONHECIMENTO DA ÁREA}

Num primeiro momento, buscamos conceituar a conformação da paisagem do trecho do bairro, aonde estamos atuando, através de análises sintéticas de sua estruturação urbana, principalmente no que diz respeito a:

Estrutura urbana;

Esquemas e fluxos de circulação;

Usos e atividades predominantes;

- Conformação do espaço construído;

Principais marcos e referenciais.

Essas análises foram possíveis através de estudos e levantamentos realizados pela equipe do projeto e são ilustradas a seguir. 
Croquis 1 - Inserção no espaço de entorno

\section{ZONA NORTE}
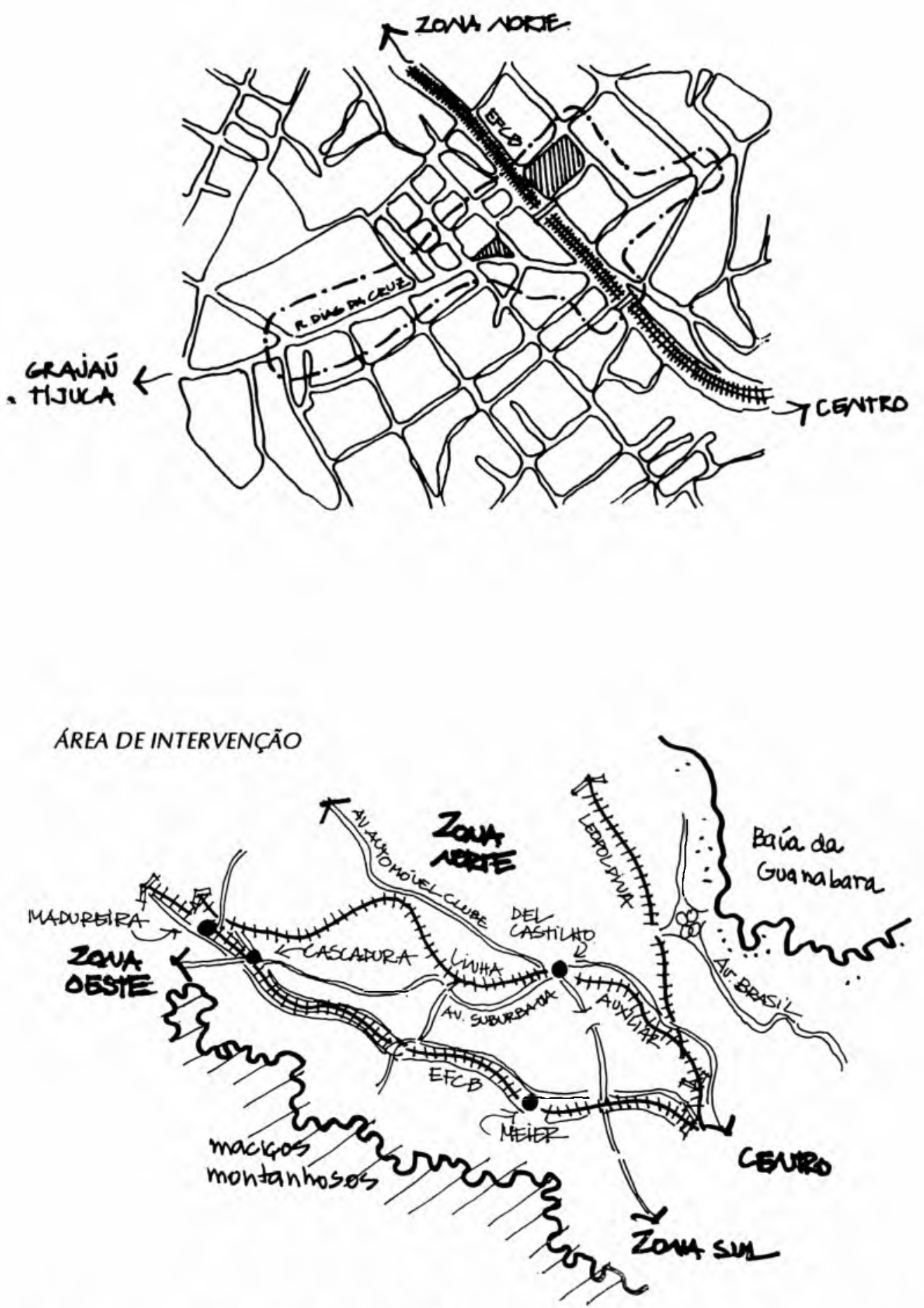

Paisagem Ambiente Ensaios São Paulo n. 8 p. 47 - 66 dez. 1995 
Croqui 2 - Esquema e fluxos de circulação.

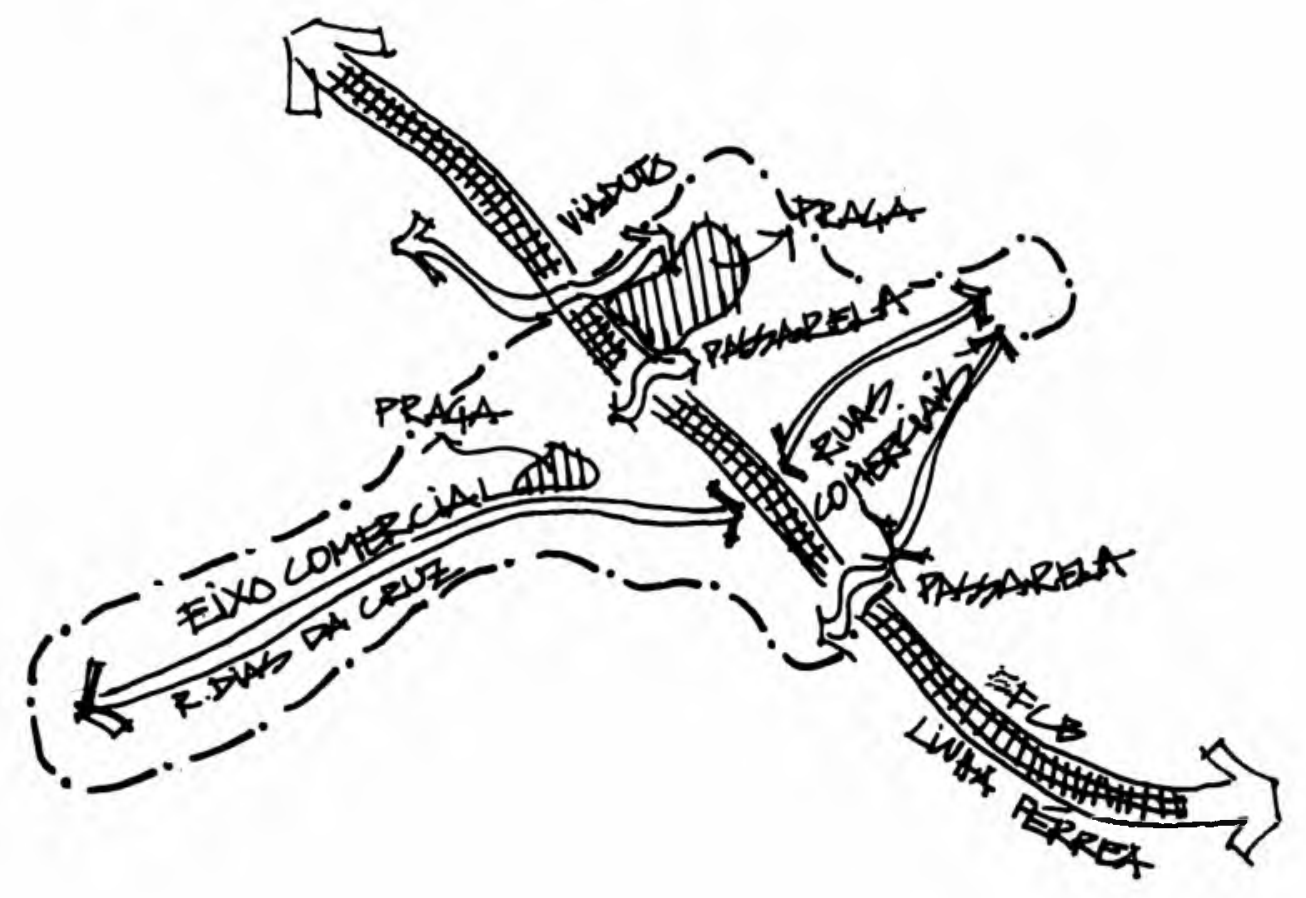

Croqui 3 - Usos e atividades.

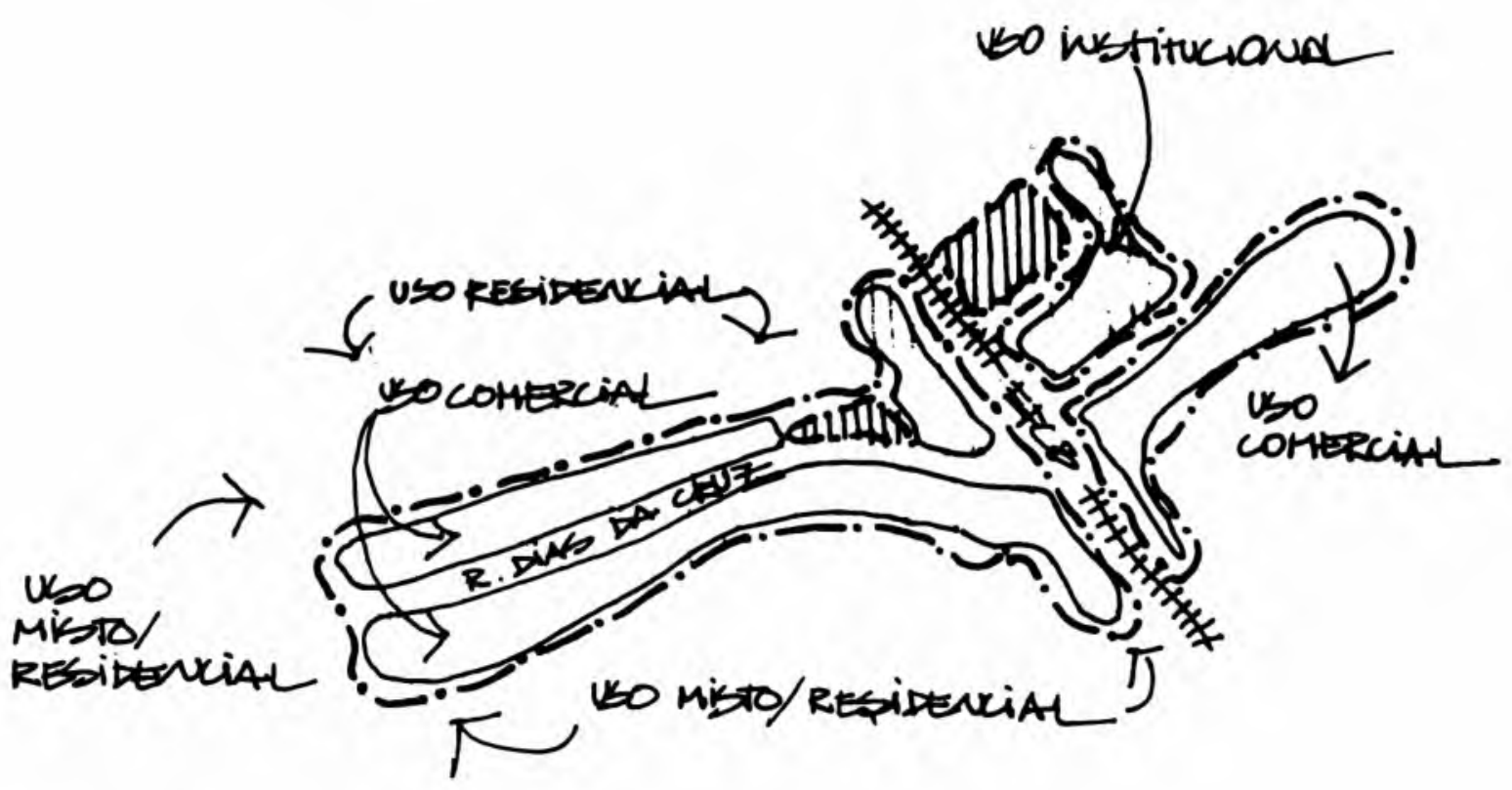


Croqui 4 - Conformação do espaço construído.

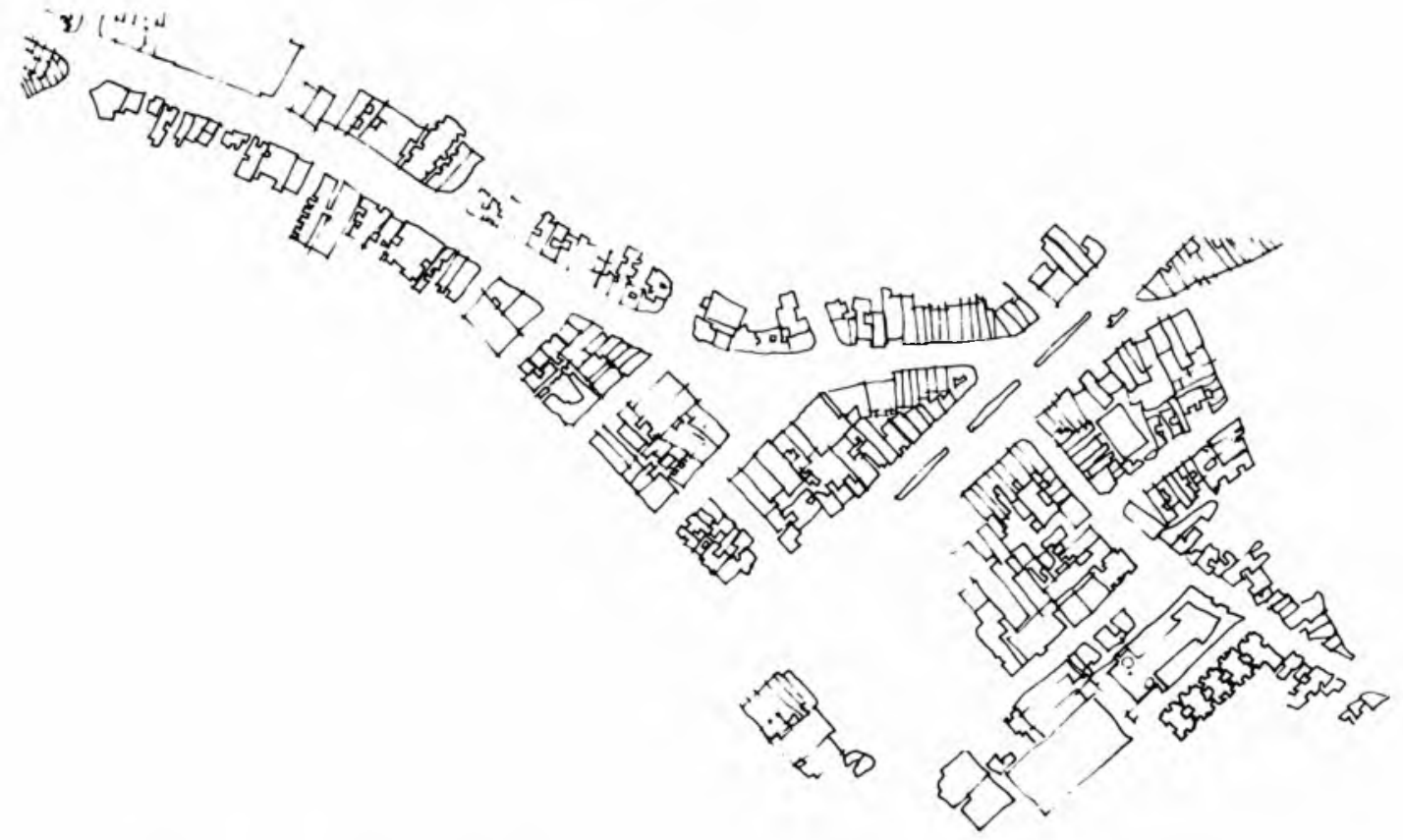

Croqui 5 - Marcos e referencias.

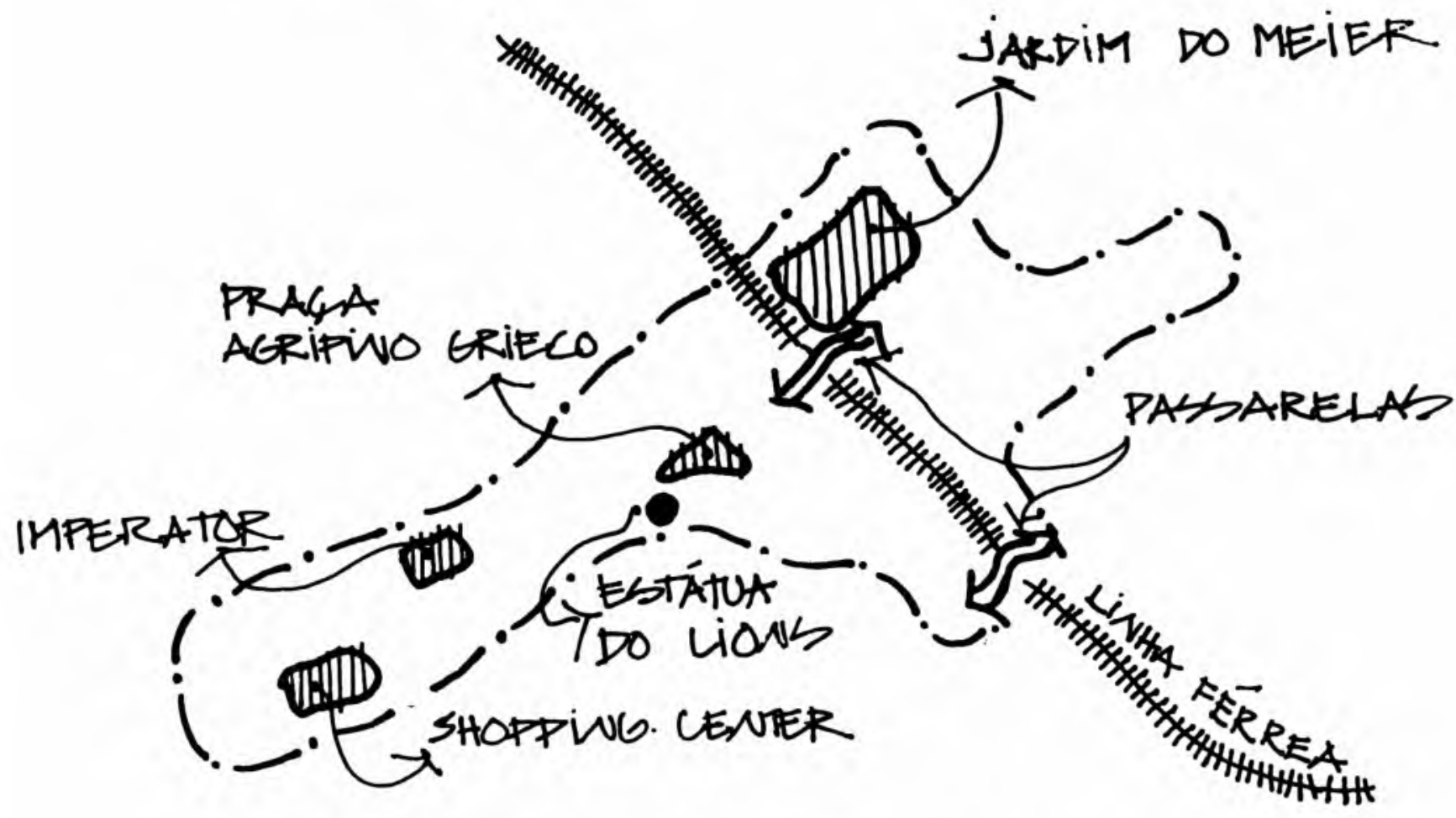

Paisagem Ambiente Ensaios São Paulo n. 8 p. 47 - 66 dez. 1995 


\section{QUALIFICAÇÃO DA PAISAGEM}

A caracterização da qualidade paisagística da área de intervenção foi realizada a partir da análise de determinados elementos, estudados isoladamente e em conjunto, de sua articulação espacial, física e visual e de sua leitura perceptiva.

Como metodologia específica para o Meier, foram enfocados;

o suporte físico natural;

o conjunto dos elementos construídos definidores do enquadramento paisagístico;

as áreas livres de edificação;

os elementos de vegetação, especialmente, a arborização viária;

o clima;

o tempo.

O cruzamento desses levantamentos levou à identificação de três conjuntos paisagísticos predominantes, com características peculiares, definidos basicamente pelas ruas mais importantes e pelas áreas de uso público e institucional.

- Rua Dias da Cruz: o trecho entre o largo do Meier, praça Agripino Grieco e rua Hermengarda, onde se localiza a estátua do Lions, delimitado como ponto exemplar do projeto; o "corredor edilício" da praça Agripino Grieco até o shoppingcenter do Meier, caracterizado como canal de circulação, enquadrado por edificações de padrão construtivo elevado, apresentando densificação construtiva, concentração comercial e incidência maciça de camelôs.

- Ruas Amaro Cavalcanti e Arquias Cordeiro: perfis caracterizados pelo alinhamento de sobrados e edificações comerciais de um lado e a estrada de ferro, do outro. 
- Rua Lucídio Lago: perfil caracterizado pelo alinhamento de sobrados comerciais dos dois lados.

- Área compreendida entre o Jardim do Meier, Hospital Salgado Filho, a estação ferroviária, passarelas e viadutos: trecho de abertura visual e de conexão entre "um lado" e o "outro lado" da estrada de ferro, entre "um" lado e o "outro" do bairro.

O croquis abaixo resume algumas conclusões gerais sobre a qualidade paisagística da área, obtidas na fase de levantamento.

Croqui 6 - Diagnostico paisag'stico.

i. i conjuntos paisagísticon



AREAS LIVRES PÚBLICAS

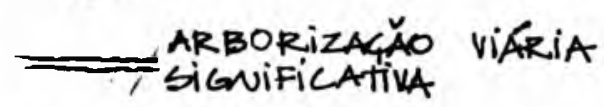

$\leftarrow \rightarrow \rightarrow$ PERCURSOS C/ BAixos

TPEAS COHA AMBIENTAL

INDICES DE CONFORTO

Y.1) POHENCIAIS DE ARTICULAGÄO

ÁEEas de amenizatáo

LOTES PARTICULARES

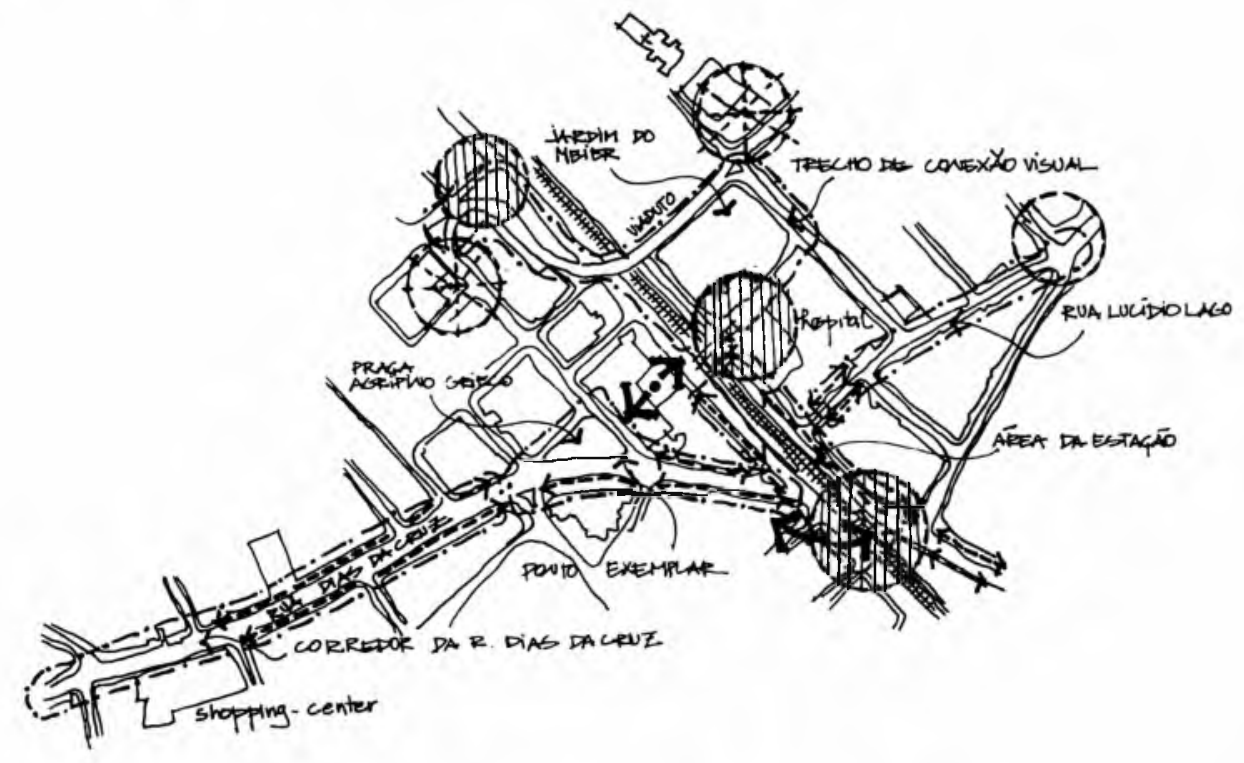




\section{DIRETRIZES DE INTERVENÇÃO}

A análise dos conjuntos paisagísticos, descritos acima, de seus principais problemas e potenciais, e das características dos espaços públicos que apresentam possibilitou formular as seguintes diretrizes gerais para intervenção no Meier:

- a articulação das áreas livres públicas existentes, incluindo ruas, praças e largos, visando integrá-las fisica e visualmente e possibilitando conectar os dois lados do bairro, a leste e a oeste da estrada de ferro;

- o reforço da qualidade paisagística das áreas livres públicas atuais e incentivo à criação de locais de amenização, decorrentes de modificação de traçado e circulação viária;

- a criação de espaços de descanso e convívio através do desenvolvimento de um sistema integrado de pocket-plazas, e melhorias de travessias e percursos de pedestres obtido pela solução de rampas, passarelas e passagens, buscando favorecer a atividade comercial e de lazer presentes na área e aumentar a atratividade de novos usos;

- o incremento às atividades de lazer e recreação, observandose os diversos grupos de usuários e atividades;

- o aumento da arborização viária, utilizando o tratamento da vegetação como alternativa para a integração e continuidade visual, além dos reflexos climáticos decorrentes;

- a adequação das condições de plantio e manutenção das espécies vegetais;

- a valorização de monumentos e marcos existentes, e a criação de outros elementos significativos como meios de referenciar e identificar espaços de uso significativos, e contribuindo para o melhor reconhecimento da área. 

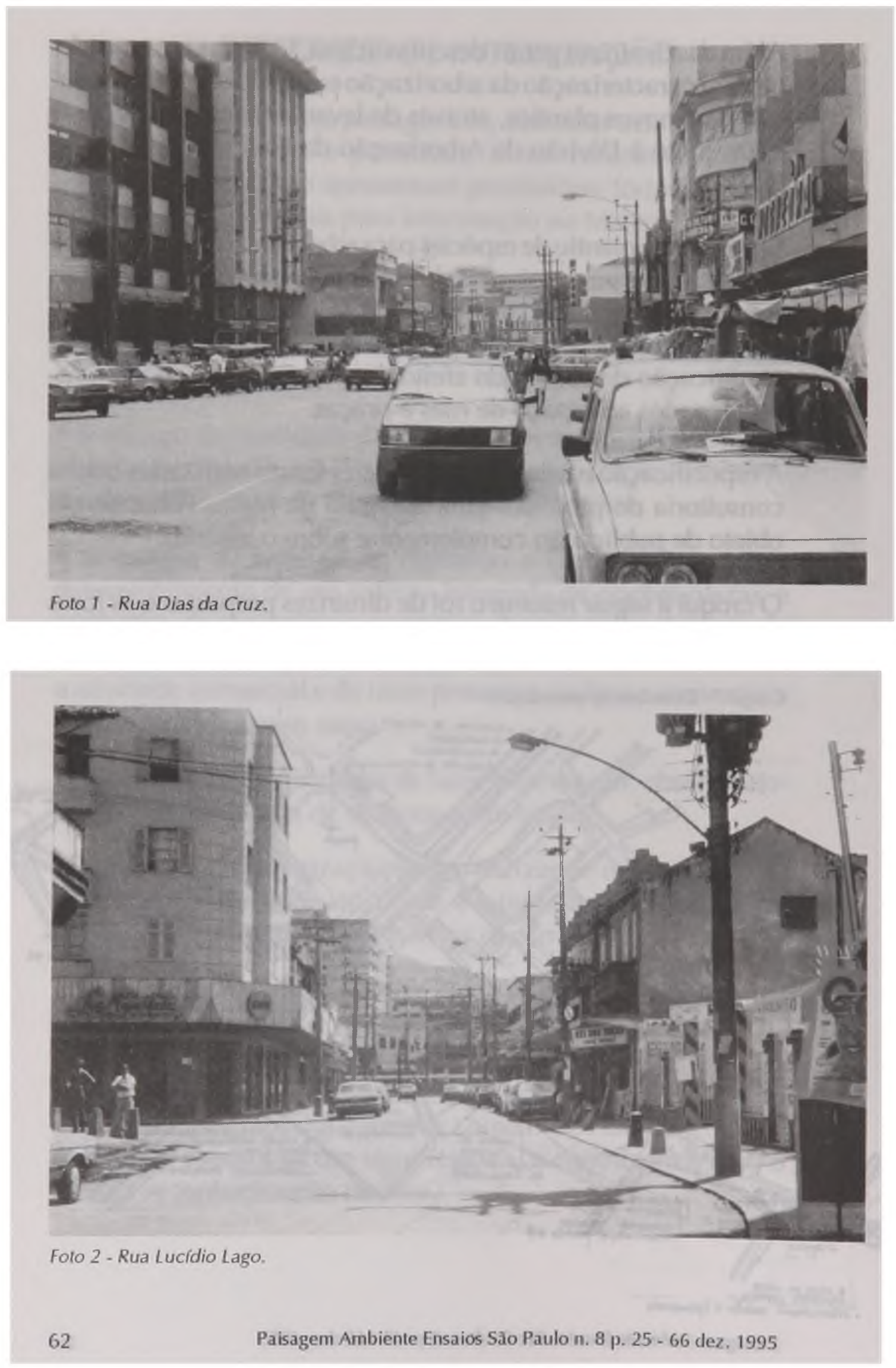


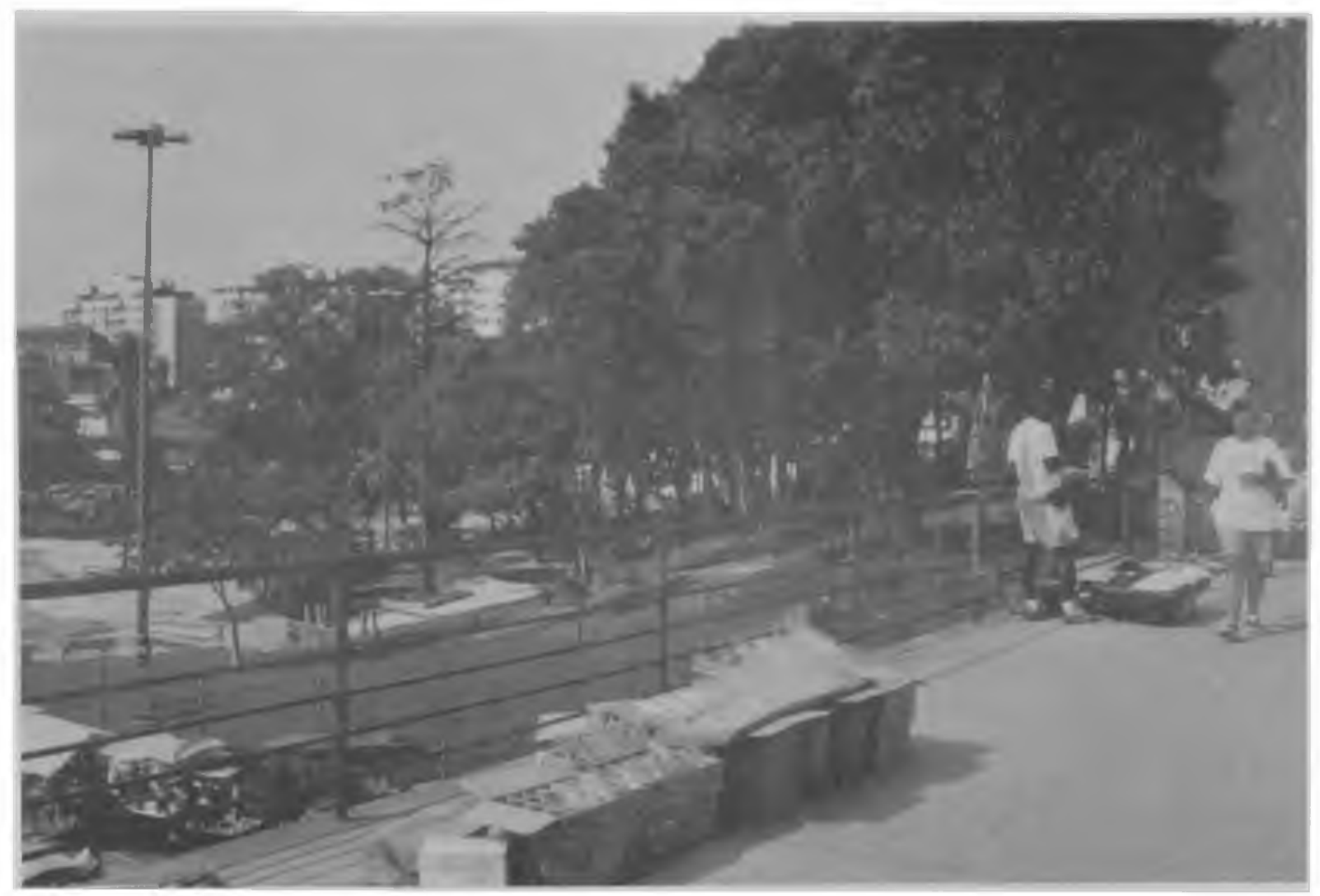

Foto 3 - Jardim do Meier.

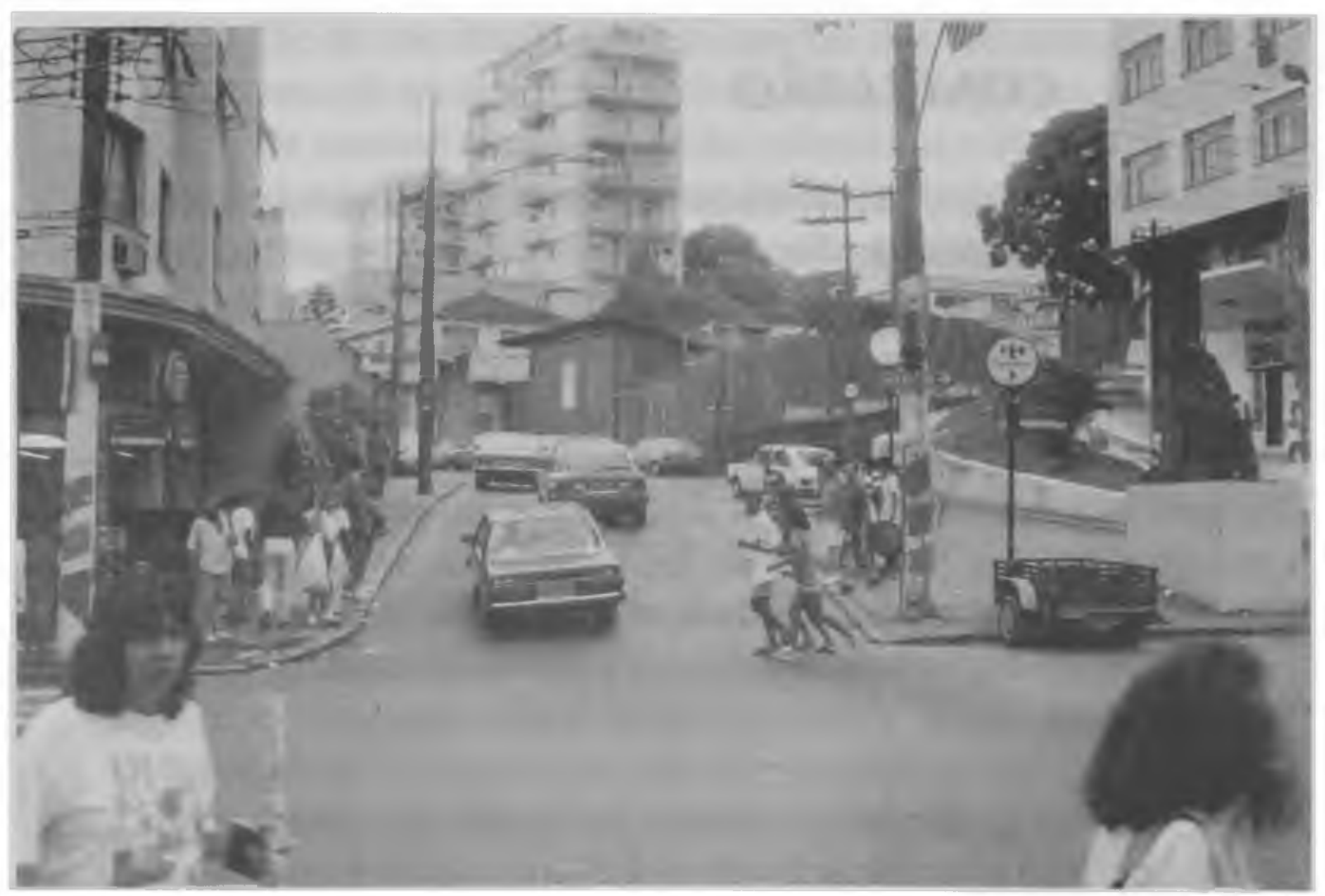

Foto 4 - Estátua do Lions. 


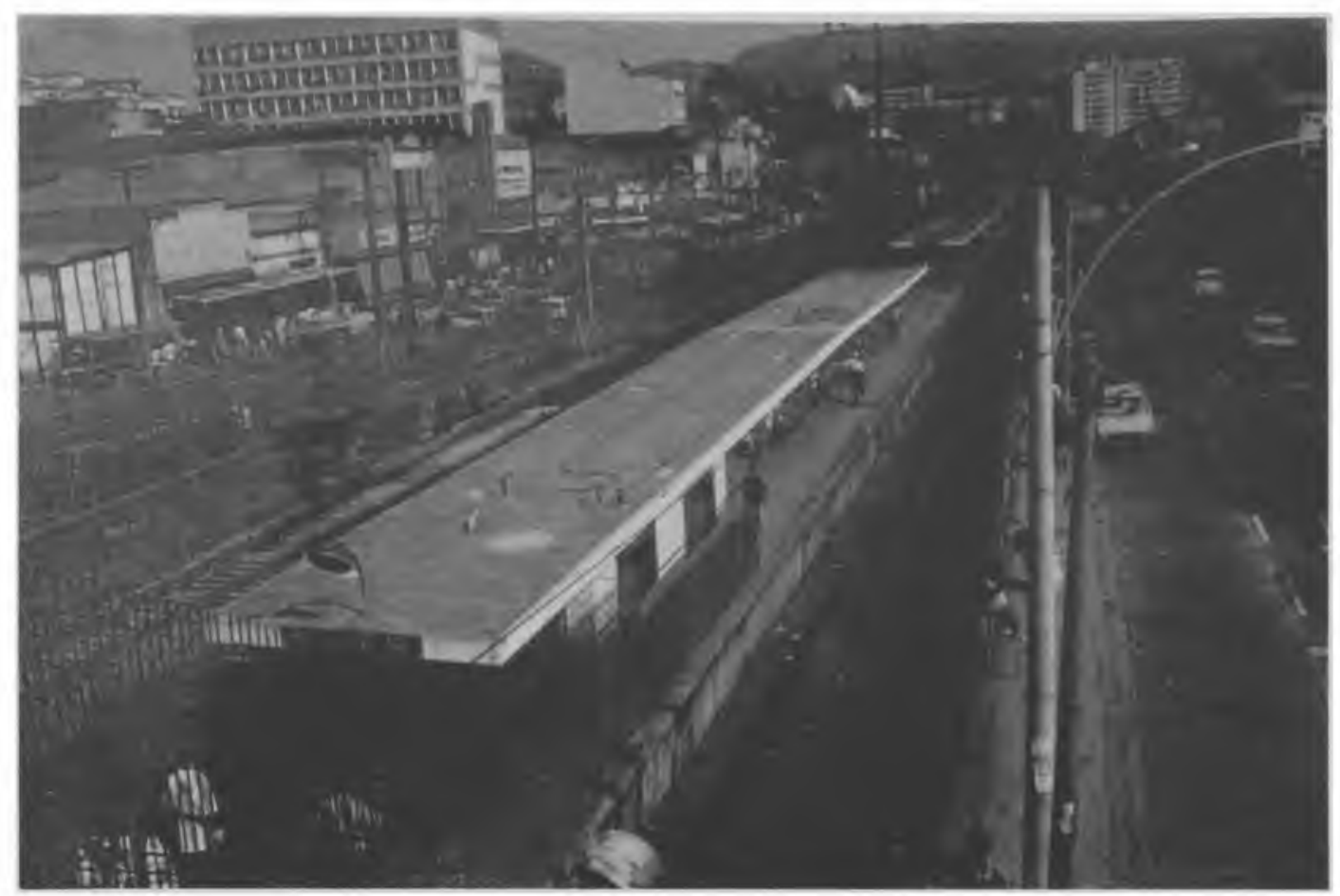

Foto 5 - A estação ferroviária.

\section{CONCLUSÃO}

De maneira sucinta, procuramos ilustrar o desdobramento das etapas anteriores através dos desenhos em anexo, pranchas 03 , 04 e 05, que resumem as propostas enviadas à IPLANRIO, para a etapa de anteprojeto.

Algumas modificações foram realizadas na etapa de detaIhamento. Essas modificações dizem respeito principalmente à adequação das propostas às necessidades do sistema de circulação viária, e aos requisitos de acessibilidade a toda população, em especial aos usuários portadores de deficiência física e visual.

Assim, a pavimentação, o acesso às áreas de amenização criadas, o tipo e a localização do mobiliário, dos equipamentos urbanos e da arborização atendem aos objetivos de orientar e 
adequar os espaços livres para que possam ser vivenciados pelo público, com o menor grau possível de barreiras e restrições.

É necessário ressaltar que não cabe ao detalhamento de um projeto paisagístico deste porte reverter os efeitos negativos à paisageme ao ambiente urbanos, ocasionados pela aplicação de uma legislação urbanística pouco ou nada responsiva aos mesmos.

A configuração básica e a qualidade paisagística atuais do espaço estudado foram estruturadas inicialmente, além de seus aspectos geomorfológicos, pela implantação da linha férrea e pela maneira como os terrenos adjacentes a ela foram sendo densamente loteados e ocupados, pelo modo como os espaços públicos foram sendo cada vez mais apropriados pelos sistemas de transportee circulação viária, pela crescente descaracterização de tipologias urbanísticas e arquitetônicas peculiares à área em questão e pela histórica falta de investimentos públicos destinados a esse bairro e demais setores da zona norte do Rio.

Buscou-se, dentro dos limites da intervenção proposta e com a elaboração de seu detalhamento que faz das calçadas o principal universo de apropriação pública, atenuar aspectos negativos através da neutralização da aridez climática e visual; do controle da ocupação dos espaços públicos; do favorecimento e valorização do uso desses espaços pelos pedestres; da introdução maciça de arborização viária; da valorização de marcos de referência e de apropriação perceptiva.

Modificações mais substanciais na configuração da paisagem urbana só serão possiveis a partir do momento em que a legislação, que regulamenta a produção do espaço construído, for revista e reformulada segundo princípios que não visem apenas à ocupação do espaço no lote individual, como também privilegiem o resultado desta ocupação em relação à cidade, às imagens e aos impactos que representam em relação ao conjunto urbanístico e paisagístico onde se inserem. 


\section{NOTAS}

(1) No caso do Meier, cujo projeto foi desenvolvido pela M \& T - Mayerhoffer \& Toledo - Arquitetura, Planejamento e Consultoria Ltda., essa tarefa ficou a cargo do arquiteto Vicente Del Rio, coordenador geral e também responsável pelas propostas de desenho urbano, e do arquiteto Luiz Carlos Toledo, responsável pelo planejamento urbano.

\section{BIBLIOGRAFIA}

ABBUD, Benedito. Vegetação e projeto: estudo de caso em São Paulo com as reflexões de um arquiteto. São Paulo, 1986. Dissetação (Mestrado), Faculdade de Arquitetura e Urbanismo, Universidade de São Paulo.

ASHIHARA, Yoshinobu. El diseño de los espaços exteriores. Barcelona: Gustavo e Gili, 1992.

CENIQUEL, Mario. Paisagem e habitat. In: Paisagem e Ambiente, n. 4. São Paulo: FAUUSP, 1992.

DEL RIO, Vicente. Introdução ao desenho urbano no processo de planejamento. São Paulo: Pini, 1990.

MACEDO, Silvio S.. A vegetação como um elemento de projeto. In: Paisagem e Ambiente. n. 4. São Paulo: FAUUSP, 1992.

MAGNOLI, Miranda M. Espaços livres e urbanização: Uma introdução a aspectos da paisagem metropolitana. São Paulo, 1982. Tese (Livre-docência) Faculdade de Arquitetura e Urbanismo, Universidade de São Paulo. 